\title{
B-27 Thorax FE model for older population
}

\author{
Hyung Yun Choi, Hongik University \\ Inhyeok Lee, ESI Korea
}

The objective of this study is to collect precise material and structural properties of older population and build a anatomically detailed finite element thorax model to predict crash induced chest injuries. Whole twelve ribs in right side of ribcages from seven fresh cadavers were prepared for microCT scan and three-point bending test. The thickness distribution of cortical bone was measured from microCT images. Nine cross sections in the axial direction and sixteen points along the circumferences in each cross section were sampled to measure the cortical bone thicknesses distribution. Each rib was dissected equally into the three pieces (anterior, lateral, and posterior) for three-point bending test. Bending stiffness and fracture moment were measured and statistically analyzed with regions (i.e., anterior, lateral, and posterior in axial direction) and rib levels. A finite element thorax model was built by taking these detailed material and geometric information into consideration. The rib fracture behavior was simulated by modeling both cortical and trabecular bones using elasto-plastic with damage material type (EWK in Pam-Crash). Model response to impact (Kroell's frontal pendulum) and dynamic (Kent's hub, distributed, single and double diagonal) loadings is provided in this paper.

Key Words: older population, thorax injury, microCT scan, FE eldenly model

\section{Introduction}

Older occupant (over 65 years of age) had almost three times higher injury risk for thoracic region than adult (24-54 years old) occupants when they were belted during the frontal crash accident. ${ }^{[1]}$ However this trend disappeared for unbelted occupants as shown in Fig. 1, which implies that the shoulder belt restraining might be too strong considering the lower injury tolerance of the elderly chest than the adult group.

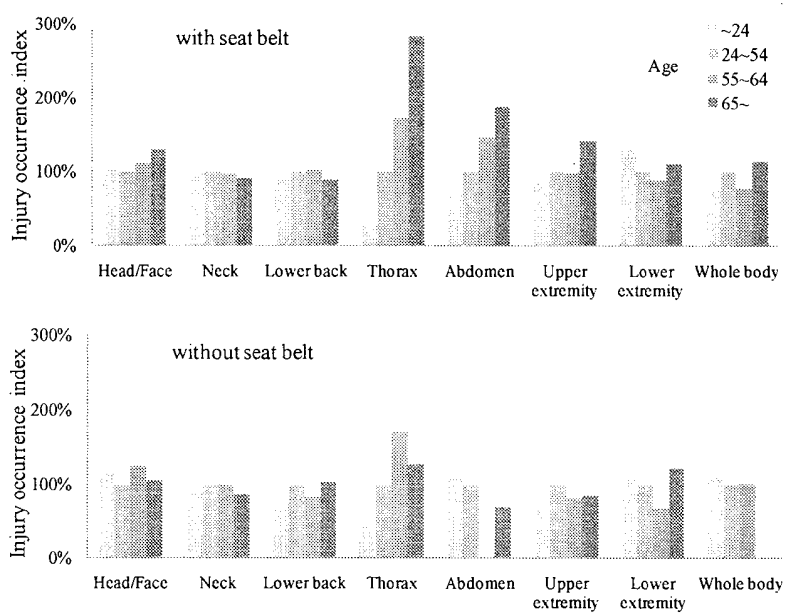

Fig. 1 Comparison of injury occurrence index between belted and unbelted occupant

Zhou et al. ${ }^{[2]}$ presented that the reduction in injury tolerance from the young age group to the elderly group is approximately $20 \%$ under blunt frontal impact loading conditions and is as much as $70 \%$ under belt loading conditions because of the degradation of mechanical properties with age due to the increasing porosity and decreasing mineral contents in bone and Wang et al. ${ }^{[3]}$ found that number of rib fractures for elderly in frontal crash accidents increased with a statistical significance comparing with those of non-elderly group. Analyzing the NASS data, Mertz and Dalmotas ${ }^{[4]}$ proposed a more effective chest protection for older occupants in frontal collisions with a reduced shoulder belt limit force since the current belt design is mostly based on younger population and therefore the restraining is too severe to elderly who have relatively fragile musculoskeletal structures.

However, the analytic assessment of crash induced injury risk for older population is currently quite limited since there is no available surrogate representing older occupant. By virtue of the efficient aspect in development time and cost of the CAE analysis such as finite element simulation, utilizing a digital elderly human body model could be a realistic and preferred approach. Kent et al.[5] modified $\mathrm{H}$-model[6], an anatomically detailed finite element human body model for crash safety simulation, to represent the chest characteristics of older human body by changing rib angle, material properties of the cortical and trabecular rib bone, and the thickness of the cortical shell of the ribs. From their parametric study, it was found that the older people were expected to have decreased rib fracture tolerance due to the consequence of aging which were morphologic and physiological property changes of tissues. Tamura et al. ${ }^{[7]}$ also developed a human thoracic FE model of the elderly occupant based on the $50^{\text {th }}$ percentile male model, THUMS (Total HUman body Model for Safety) and confirmed that a digital human body model could be utilized for predicting thoracic hard tissue injury by taking into account the decreased bone strength due to aging. However either Kent et al. ${ }^{[5]}$ and Tamura et al. ${ }^{[7]}$ did not applied "real" elderly human body model but adult models that were adjusted for thoracic bone properties and shape to represent weakened characteristics of the older population.

During the previous stage of this study ${ }^{[8]}$, a standard size and shape of Korean elderly model by analyzing the $5^{\text {th }}$ national anthropometric survey database (SizeKorea, '03-'04) was defined and a subject who had a similar age and body dimensions to the standard elderly model were selected as a test participant for the acquisition of external and internal body geometries. Table 1 compares age and major body dimensions of standard Korean elderly model and the test participant. Fig. 2 shows the external skin shape and the skeletal structure of the test participant in a driving posture. Whole body $3 \mathrm{D}$ laser scanner was used to acquire external skin shape while the skeletal geometry was obtained by reconstructing CT images of the test participant. These external skin shape and internal skeletal geometries were further utilized to build a finite element model. The detailed modeling and validation process are introduced in this paper.

Table 1 Age and body dimensions of standard Korean elderly model and the test participant

\begin{tabular}{|c|c|c|}
\hline Items & SizeKorea $^{*}$ & Test participant \\
\hline Age $^{* \star}$ & 72.4 & 71 \\
\hline
\end{tabular}




\begin{tabular}{|c|c|c|}
\hline Height $(\mathrm{cm})^{\star \star}$ & 162.8 & 162.7 \\
\hline Weight $(\mathrm{kg})^{\star \star}$ & 63.0 & 63.9 \\
\hline Sitting height $(\mathrm{mm})^{\star \star \star}$ & $787 \sim 917$ & 856 \\
\hline Waist height $(\mathrm{mm})^{\star \star \star}$ & $914 \sim 1005$ & 977 \\
\hline Bust girth $(\mathrm{mm})^{\star \star \star}$ & $847 \sim 973$ & 920 \\
\hline Waist girth $(\mathrm{mm})^{\star \star \star}$ & $780 \sim 932$ & 873 \\
\hline
\end{tabular}

$*: 5^{\text {th }}$ national anthropometric survey ('03-'04)

**: Average of 527 males over 65 years old in SizeKorea DB

$* * *$ : Minimum and maximum in dimensions of 47 elderly subjects in SizeKorea DB those who had height and weight within the range of mean $\pm \sigma / 3$ (one third of standard deviations)
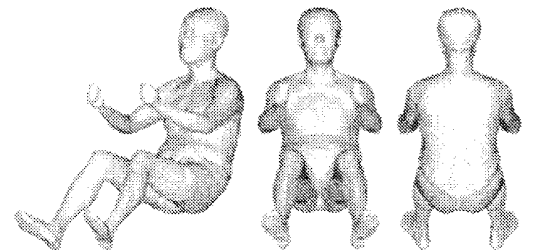

Fig. 2 Scanned image of the elderly test participant in a driving posture (left) and section image (right)

\section{PMHS rib test}

Kemper et al. ${ }^{[9]}$ reported their measurement of cortical bone thickness distributions and mechanical strength from the cadaver rib coupons. In their study, 48 coupons for 3 -point bending tests were obtained by dissecting anterior and lateral regions of $4^{\text {th }}$ through $7^{\text {th }}$ ribs of six male cadavers ranging from 42 to 81 years of age. From cross-sectional MicroCT images, the measured cortical bone thicknesses for anterior region of ribs were found to range from $0.46 \mathrm{~mm}$ (Inferior, SD $=0.13 \mathrm{~mm}$ ) to $0.87 \mathrm{~mm}$ (Interior, $S D=0.26$ ) in average. The lateral region of the ribs showed about $30 \%$ higher cortical bone thickness than the anterior region. From the statistical analysis, the cortical thickness of anterior specimen was found to be significantly less than lateral specimen at the interior $(p<0.01)$, superior $(p=0.03)$, and inferior $(p<0.01)$. The interior and exterior cortical bone thickness were also found to vary significantly with respect to rib level for anterior specimens $(p<0.01)$, but not for lateral specimens. Since it was concluded that there were no significant difference in tensile mechanical properties of cortical bone with respect to region of rib level within an individual, the geometric bone thickness variation remains as a quite important factor for the deformation and failure response of the thorax.

The pixel resolution of CT images to capture the shape and position of skeleton in our study was $0.97 \mathrm{~mm}$ and it thus could not provide the detail information of cortical bone thickness distribution. So, it was decided to collect the necessary information about the rib configuration such as cortical bone thickness and cross sectional area from fresh cadavers' specimen. Seven domestic fresh cadavers that had similar anthropometry and age of standard $50^{\text {th }} \%$ tile elderly were employed (Table 2). In order to take microCT images, $3^{\text {rd }}$ to $11^{\text {th }}$ ribs were dissected equally into three regions, i.e., anterior, lateral and posterior. For $2^{\text {nd }}$ and $12^{\text {th }}$ ribs, only the middle portion was prepared as a lateral region and the $1^{\text {st }}$ rib was not included in this study. Each rib coupon was also used for 3-point bending test for measurement of stiffness and strength. These geometric and mechanical characteristics of elderly ribs were statistically analyzed along the levels and regions.

Table 2 Data for PMHS used in rib testing

\begin{tabular}{|c|c|c|c|c|}
\hline & Max. & Min. & Mean & SD \\
\hline Age (year) & 75 & 64 & 71.3 & 3.86 \\
\hline Stature $(\mathrm{cm})$ & 170 & 160 & 165.3 & 4.15 \\
\hline Mass $(\mathrm{kg})^{\star}$ & 57 & 40 & 50.9 & 6.77 \\
\hline
\end{tabular}

${ }^{*}$ PMHS weighs less due to dehydration

\subsection{MicroCT scanning for the cortical bone thickness}

A high resolution in-vivo MicroCT machine was used for the scanning of the rib coupons. Sliced MicroCT images were then reconstructed to 3dimensional CAD model which presented precise external and internal geometry of the rib. Along the axial direction of the rib, nine cross sections normal to the neutral axis at equally spaced positions were virtually dissected. A custom Matlab code was used to gauge cortical bone thicknesses at the 16 sampling points along the circumference of the section (Fig. 3) by taking following steps:

1. Equally space 16 points (point $A$ in Fig. 3) along outer circumference of cross section

2. Find point $B$ on inner circumference which is the nearest one to point $A$

3. Find point $C$ at the midpoint between points $A$ and $B$

4. Locate point $D$ at the midpoint between two adjacent points $\mathrm{C}$

5. Draw vertical line from point $D$ along the thickness direction

6. Assign points $E$ and $F$ on the outer and inner circumferences for the points intersecting with vertical line

7. Measure the length of the line EF and assign it as a cortical bone thickness

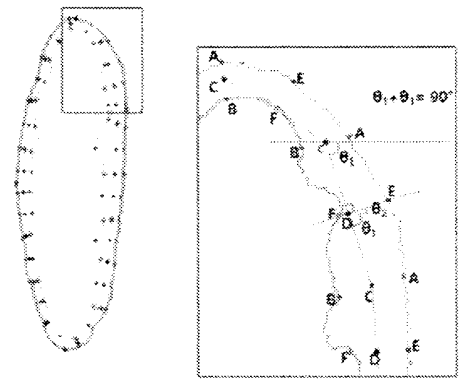

Fig. 3 Sampling and gauging the cortical bone thickness from micro CT image of rib bone

There are 144 gauged points for the cortical bone thickness of each rib: 16 sampling points along the circumference (t-coordinate in Fig. 4) in 9 cross sections (s-coordinate in Fig. 4). Figs. 5 and 6 show the thickness distributions in $s$ and $t$ coordinates, respectively. The average cortical bone thickness of seven cadavers at superior point tends to increase from anterior to posterior region as shown in Fig. 5. The thickness distribution in a cross section had "M" shape (Fig. 6) in which interior and exterior sides had 2 - 4 times thicker cortical bones than superior and inferior sides.

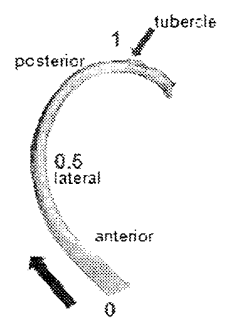

s- coordinate

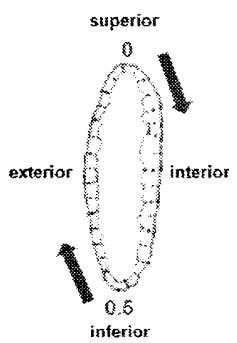

- coordinate

Fig. 4 Local coordinate definition of rib: axial direction 
(s-coordinate) and circumferential direction (t-coordinate)

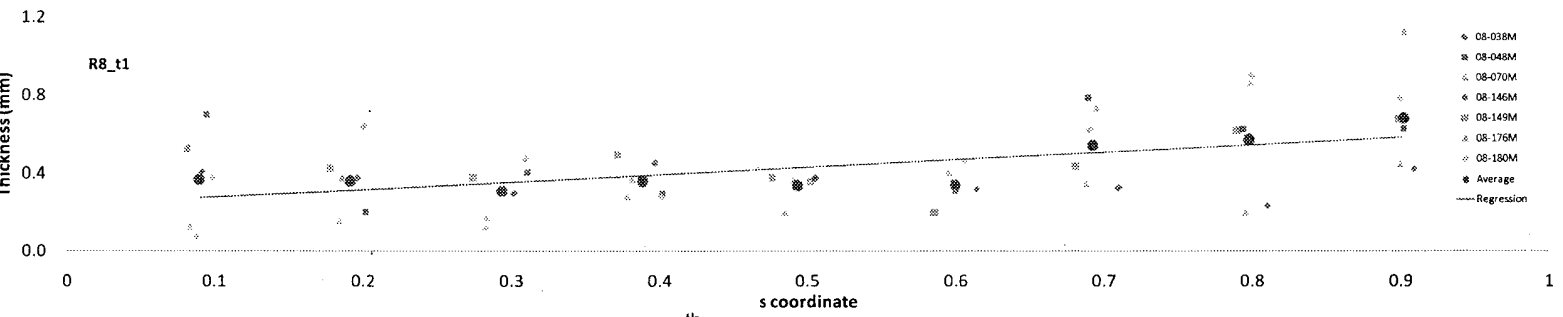

Fig. 5 Cortical bone thickness distribution of $8^{\text {th }}$ rib along the superior side in axial direction (s-coordinate) 18
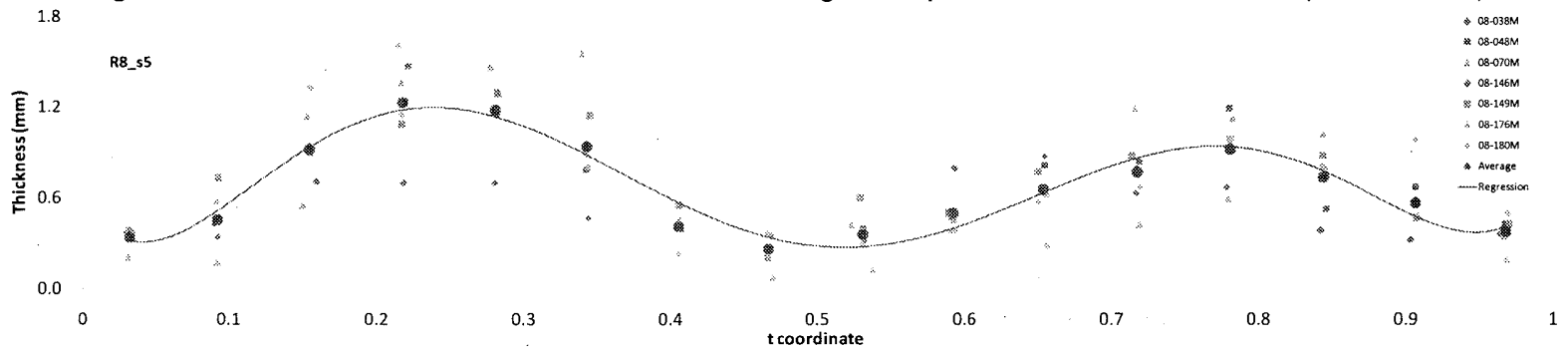

Fig. 6 Cortical bone thickness distribution of $9^{\text {th }}$ rib along the circumferential direction (t-coordinate) at a middle cross section

\subsection{3-point bending test}

Dynamic 3-point bending test was performed with the MicroCT scanned PMHS rib segments. Loading speed was set to $177.8 \mathrm{~mm} / \mathrm{s}$ which mimicked the deforming rate of ribs of belted occupant in $36 \mathrm{mph}$ frontal crash. Rib specimen was potted with PMMA at one end for pin support and simply supported at the other end as shown in Fig. 7. Force-deflection characteristics were measured during the bending test. Putting the naturally non-uniform length of each rib coupon into the simple beam theory, bending moment until fracture was computed from the measured force profile. The peak bending moment at the fracture point along the axial region of the rib shown in Fig. 8 revealed an increasing trend from anterior to posterior region with a statistical significance $(p=0.000)$. The fracture bending moment distribution with the rib level is also shown in Fig. 9. The difference of peak moment in anterior and posterior regions along the rib level was statistically significant (anterior $p=0.001$, posterior $p=0.003$ ), but not for the lateral region $(p=0.06)$.

The bending stiffness of rib segment along the axial region is shown in Fig. 10. There was a gradual increase from anterior to posterior region with a statistical significance $(p=0.000)$. The difference of bending stiffness with the rib level had statistical significance (anterior $p=0.004$, lateral $p=0.010$, posterior $p=0.000$ ).

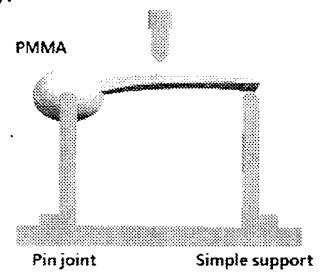

Fig. 7 Experimental setup for three-point rib bending

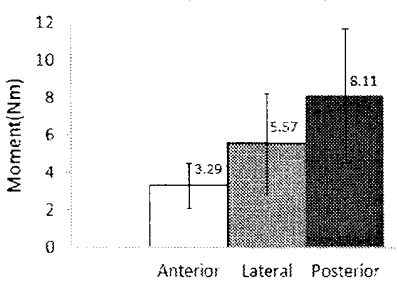

Fig. 8 Fracture bending moments at three regions

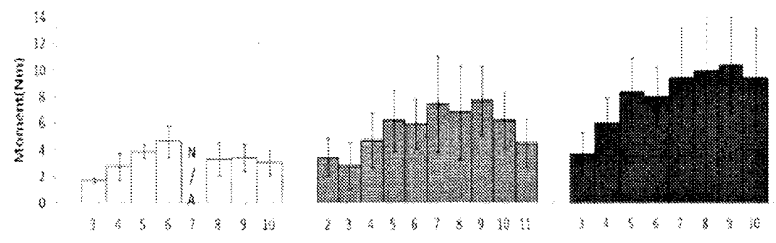

Fig. 9 Regional peak bending moments with rib levels

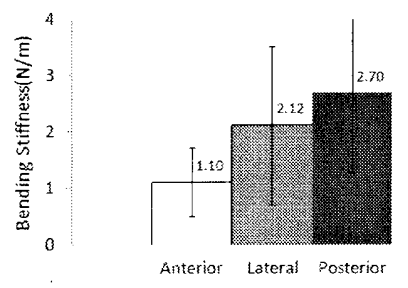

Fig. 10 Bending stiffness at three regions

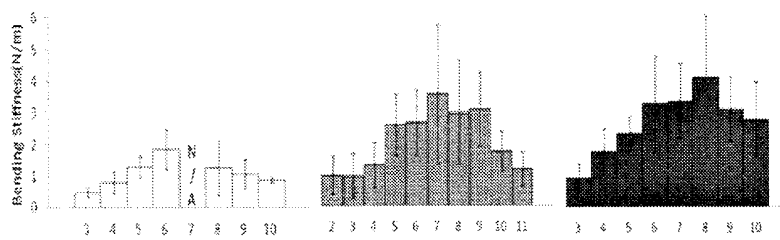

Fig. 11 Regional 3-point bending stiffness with rib levels

3. Finite element modeling of elderly thorax

3.1. Articulated rigid body modeling for representing whole body

The finite element model of elderly human body, E-model (Fig. 12) was built with torso part as fully deformable but the rest of body parts, i.e., head, neck and upper and lower limbs as rigidly articulated. As it was mentioned above the increased thorax injury risk of older occupant which was confirmed from the traffic accident statistics ${ }^{[1]}$ was to be focused while the model still keeps the computational efficiency. The external and internal geometries of the FE model were respectively based on the scanned skin shape and the reconstructed skeleton structures from CT images of the test participant who was selected as a standard elderly during the recruitment process ${ }^{[8]}$. The cortical bone thickness distribution acquired from the PMHS study described in the previous section was also assigned for the rib cage modeling. 
The other modeling details for torso organs and articulating joints for limbs were adopted from $\mathrm{H}$-model ${ }^{[6]}$.
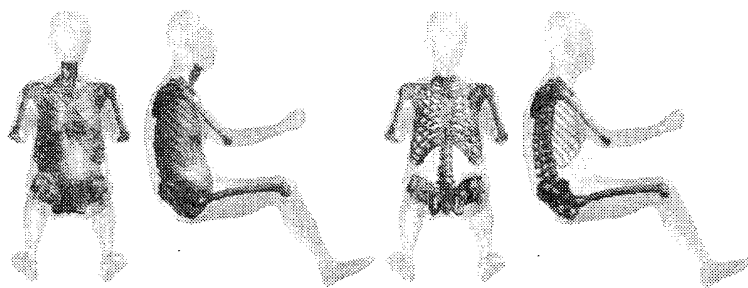

Fig. 12 Finite element elderly human body model (left: displayed with both skeleton and organs, right: displayed with skeleton only)

\subsection{Fracture modeling of rib}

The fracture behavior of rib was represented by using EWK model ${ }^{[10]}$ that predicts the fracture initiation and eventual propagation within structural components. Fracture occurs when the time integrated product of the equivalent plastic strain rate and two functions of the local stress distribution (mean tensile stress and the stress asymmetry) exceed a critical value Dc over a critical dimension Rc. EWK parameter identifier ${ }^{[10]}$ was used for the automatic estimation of mechanical properties (Table 3 ) of rib to simulate the fracture behavior in three-point bending configuration. The simulated three-point bending response of a rib segment (lateral segment of $9^{\text {th }} \mathrm{rib}$ ) shows that the failure of the rib coupon began at time $20 \mathrm{msec}$. and fractured in few milliseconds (Fig. 13). The comparisons of rib bending stiffness and failure force between simulation and experiment (average of coupons from seven PMHS) for entire rib cage are shown in Fig. 14. Simulation results correlate reasonably well with the experimental measurements for both bending stiffness and failure force. The main source of some deviation in the comparison is due to the geometric difference of ribs such as cross sectional area between the E-model and the average of PMHS coupons. The cortical bone thickness distribution averaged from PMHS was used in the rib modeling but the outer geometry itself of each rib in E-model was from the specific test participant.

Table 3 Mechanical properties of rib bones used for fracture modeling (EWK in Pam-Crash ${ }^{[10]}$ )

\begin{tabular}{|c|c|c|}
\hline Material properties & Cortical & Trabecular \\
\hline Elastic modulus $(\mathrm{E}, \mathrm{GPa})$ & 3.63 & 0.524 \\
\hline Yield strength $\left(\sigma_{\mathrm{y}}, \mathrm{MPa}\right)$ & 45.8 & 6.3 \\
\hline Tangent modulus $\left(\mathrm{E}_{\mathrm{t}}, \mathrm{MPa}\right)$ & 255 & 0.7 \\
\hline Target failure strain $\left(\varepsilon_{\mathrm{f}}\right)$ & 0.030 & 0.078 \\
\hline
\end{tabular}

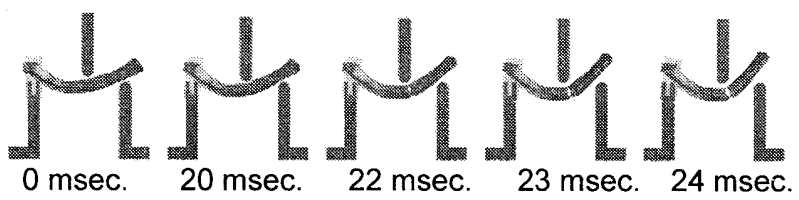

Fig. 13 Bending simulation of lateral segment of $9^{\text {th }}$ rib
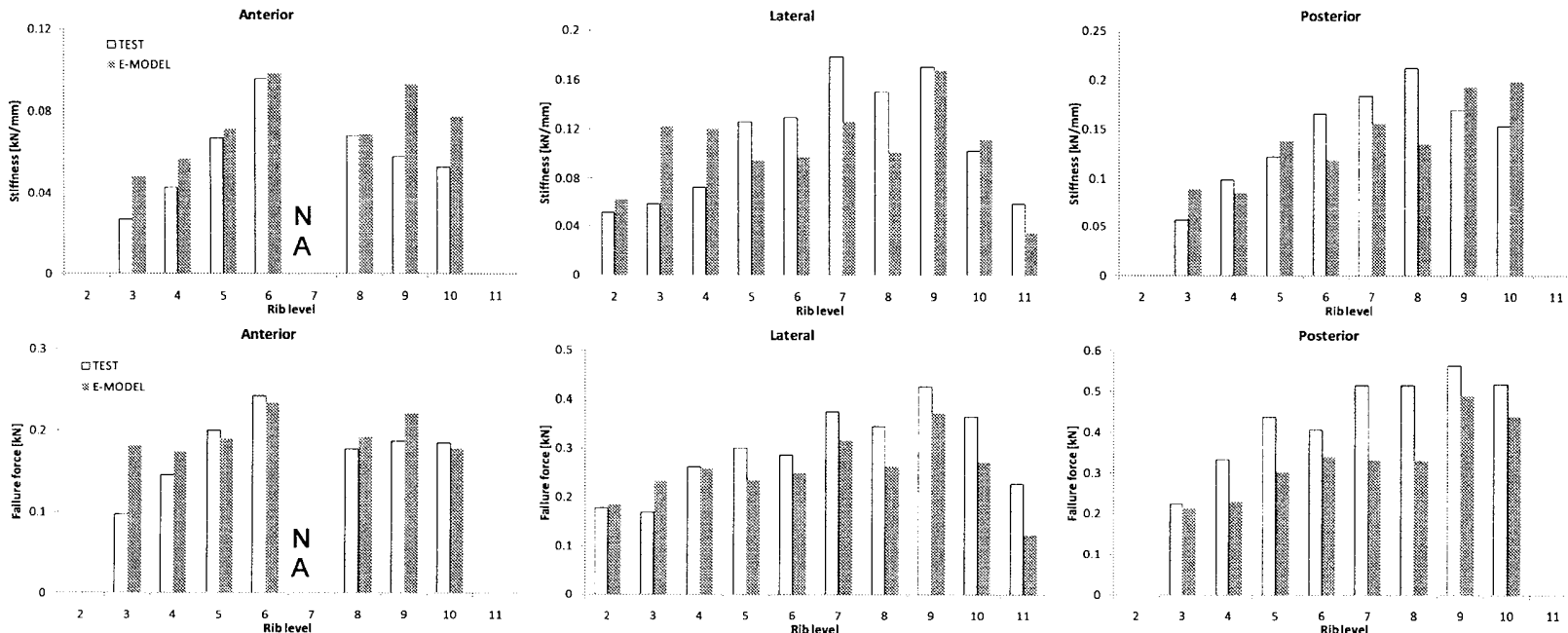

Fig. 14 Comparison of bending stiffness (top) and failure force (bottom) of ribs between simulation and experiment

\subsection{Model response to impact loadings}

In order to investigate the response of the elderly human body model to the impact loading, frontal pendulum impacts on chest (Kroell test ${ }^{[11]}$ ) were simulated. The force-deflection responses of the model for two impact velocities (c.f. $4.3 \mathrm{~m} / \mathrm{s}$ and $6.7 \mathrm{~m} / \mathrm{s}$ ) are shown in Fig. 15. The maximum chest deflections of elderly model were within the corridors of adult male $50^{\text {th }} \%$ tile size for both impact velocities. The force level in plateau region was fairly lower than the corridor for 6.7 $\mathrm{m} / \mathrm{s}$ impact case while it remained within the corridor (new corridor which removed $667 \mathrm{~N}$ shift from original ${ }^{[12]}$ ) for 4.3 $\mathrm{m} / \mathrm{s}$ impact case. The whole body motion and sectional deformation for two impact velocities are show in Figs. 17 and 18. The predicted numbers of fractured ribs were respectively 3 and 9 for two velocities, (Fig. 18). The non-symmetric rib fracture numbers and patterns are mainly due to the non-symmetric organ placement (e.g. heart).

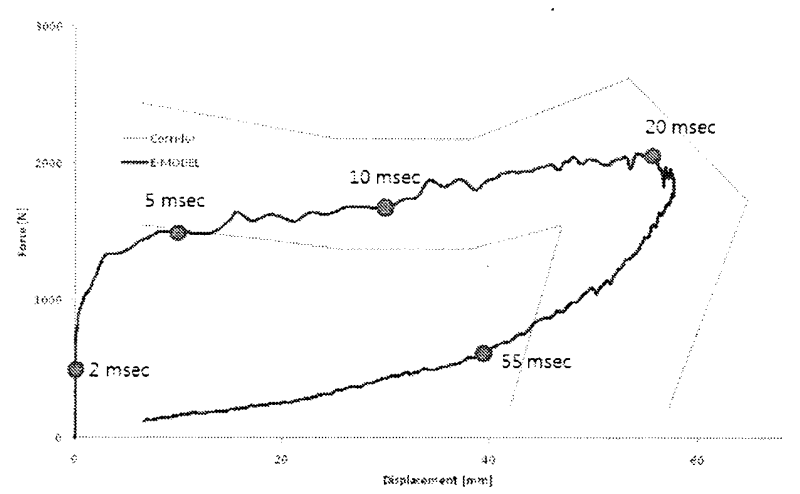




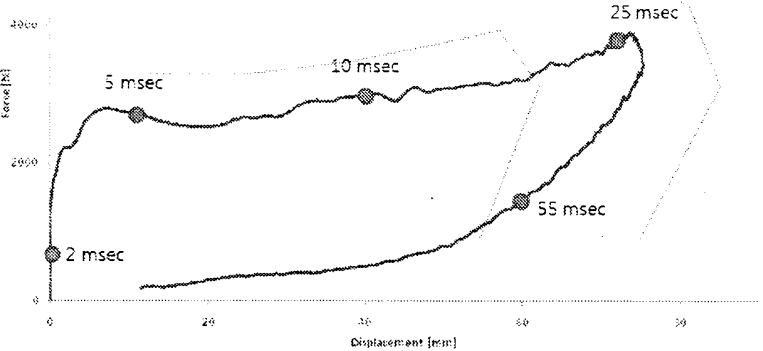

Fig. 15 Model response (F-d curve) for pendulum chest impact (Kroell test ${ }^{[12]}$ ):

Impact velocity, Top: $4.3 \mathrm{~m} / \mathrm{s}$, Bottom $6.7 \mathrm{~m} / \mathrm{s}$

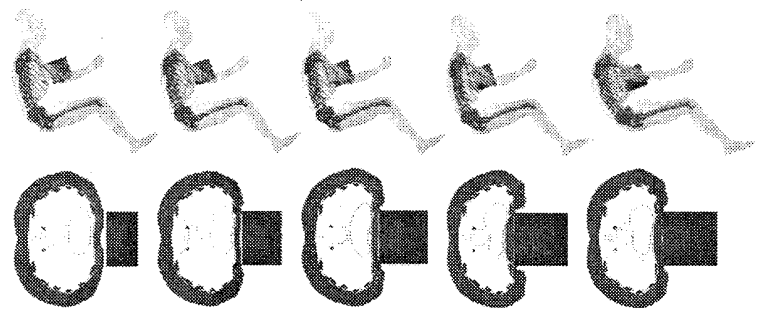

$0 \mathrm{msec} . \quad 5 \mathrm{msec} . \quad 10 \mathrm{msec} .20 \mathrm{msec} .55 \mathrm{msec}$.

Fig. 16 Model response for pendulum chest impact (Kroell test $\left.{ }^{[12]}\right)$ : Impact velocity $-4.3 \mathrm{~m} / \mathrm{s}$

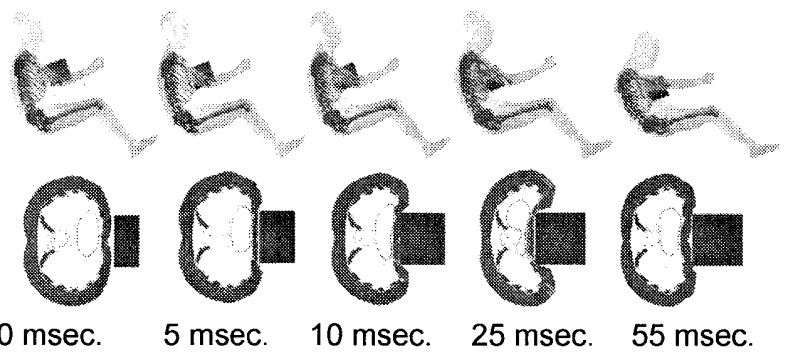

Fig. 17 Model response for pendulum chest impact (Kroell test $\left.{ }^{[2]}\right)$ : Impact velocity $-6.7 \mathrm{~m} / \mathrm{s}$
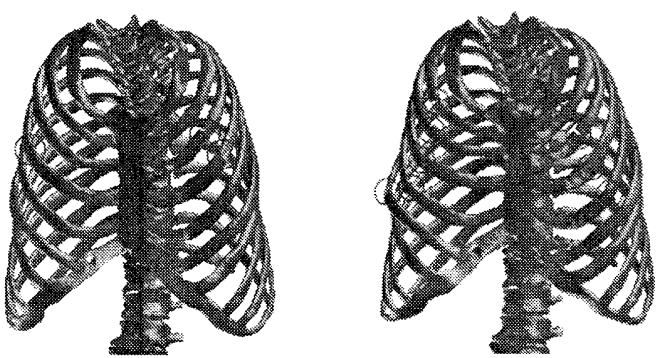

Fig. 18 Simulated rib cage deformations and fractures for frontal pendulum impact (Kroell test ${ }^{[12]}$ ):

Left $-4.3 \mathrm{~m} / \mathrm{s}$ case at $20 \mathrm{msec}$., Right $-6.7 \mathrm{~m} / \mathrm{s}$ case at $25 \mathrm{msec}$. (Rib fractures are in red circles)

\subsection{Model response to dynamic loadings}

In order to investigate the response of the elderly model to the non-impact but dynamic loading, four dynamic loadings (Fig. 19) on chest (Kent test ${ }^{[13]}$ ) were simulated. Dynamic loading speed was set to $1 \mathrm{~m} / \mathrm{s}$ to mimic the belt and airbag loading speed on chest from $30 \mathrm{mph}$ sled test. The deformed shapes of the model for four loadings are shown in Fig. 20. The posteriorly measured reaction force

which is the contact force between back of the model and underlying table in the simulation was scaled to represent $50^{\text {th }} \%$ tile male using the ratio of whole-body mass of the model ${ }^{[13]}$. These scaled posterior force-normalized chest deflections (ratio of chest deflection to the depth) are shown in Fig. 21 and they fell into the corridors from the experiment ${ }^{[13]}$ except for the end region of single belt loading case.
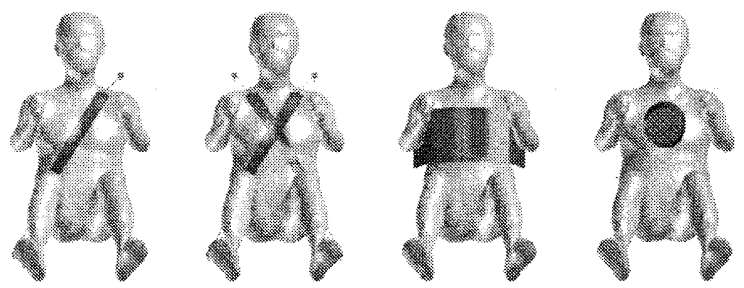

Fig. 19 Model configurations with four dynamic loadings
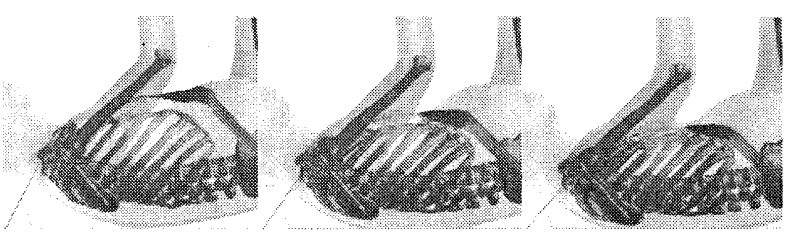

Diagonal
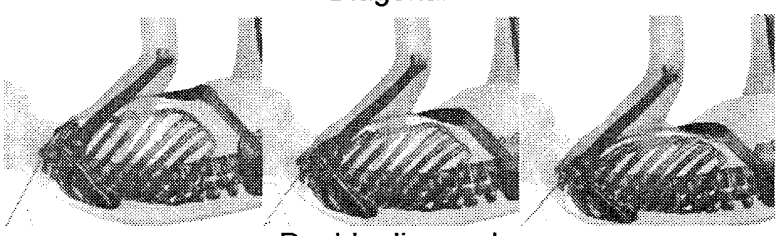

Double diagonal
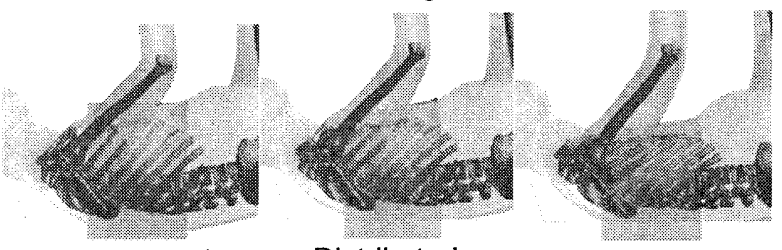

Distributed
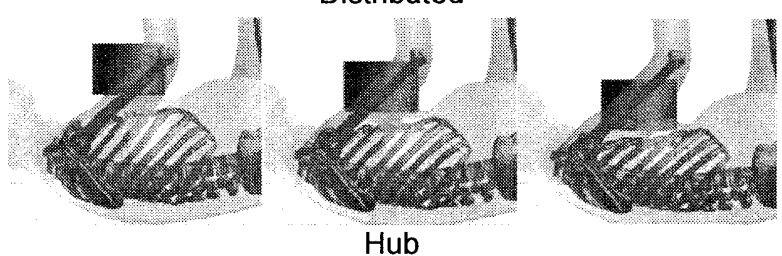

Fig. 20 Chest deflection with four dynamic loadings (Left: unformed, Center: at 10\% deflection, Right: $20 \%$ deflection)

$$
4000 \text { Diagonal }
$$

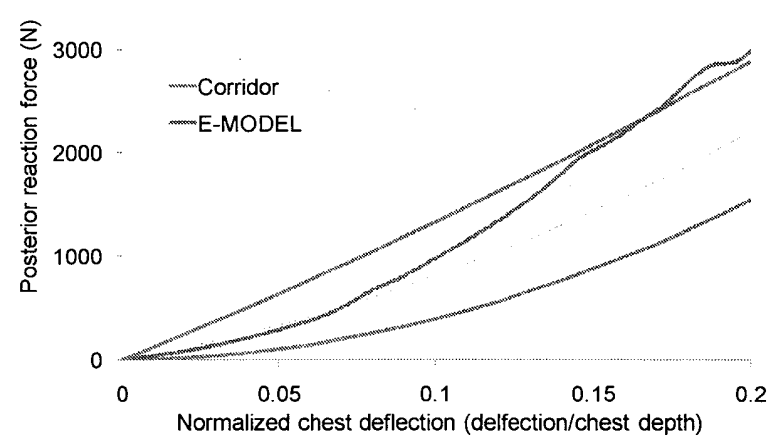



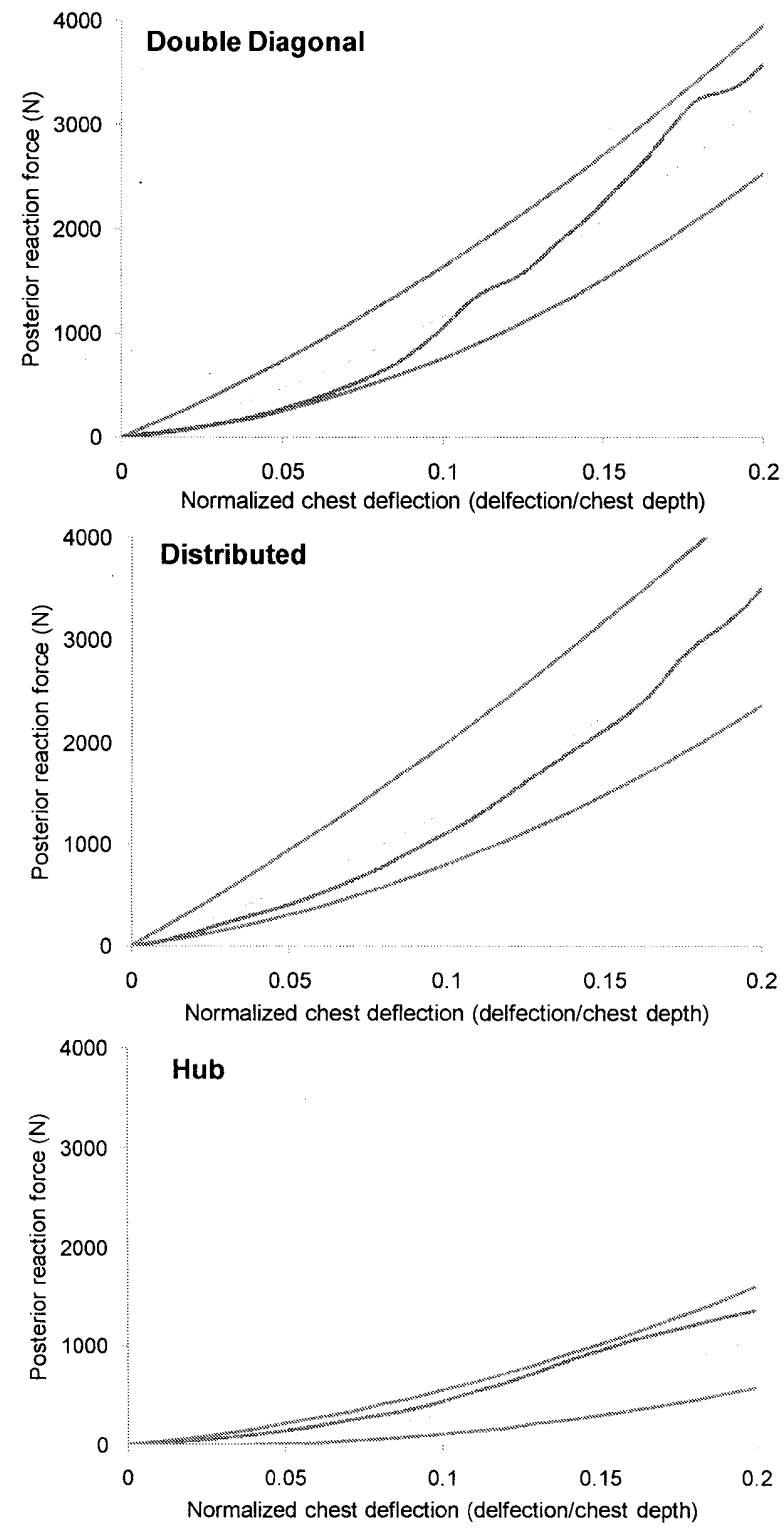

Fig. 21 Model response (mass scaled posterior reaction force-normalized chest deflection curve) with four dynamic loadings (Kent test ${ }^{[13\}}$ )

\section{Conclusion}

A finite element model of elderly human body was developed. The model represents the standard body shape and size of Korean over 65 years old male population. The detailed morphologic and material characteristics of rib cage such as cortical bone thickness distribution and mechanical strength were obtained from PMHS study while the external skin shape and internal skeletal structure were based on scanned images of a 71 years old test participant who had similar body dimensions to the standard elderly. The model was validated and identified against PMHS tests for its responses to impact and dynamic loadings on chest. It is expected that the model could be used for a virtual assessment of crash induced injury risk and a design of restraint system for the older population.

\section{Acknowledgments}

The authors would like to thank Dr. Dai-Soon Kwak at Catholic Institute Applied Anatomy for supplying PMHS rib specimens and conducting the dissections. This research was supported by a grant (06 C01) from Implementation of More Efficient Transportation System Program funded by Ministry of Land, Transport and Maritime Affairs of Korean government.

\section{Reference}

[1] Hong, S. and Cho, K. (2009). A Study on Injury Characteristics of Elderly in Car-to-Car Frontal Crashes. Transactions of KSAE, Vol. 17, No. 2, pp.90-97

[2] Zhou, SW, Rouhana, S.W. and Melvin, J.W. 91996) Age effects on thoracic injury tolerance", SAE Technical Paper series 962421

[3] Wang, S.C., Siegel, J.H., Dischinger, P.C., Loo, G.T., Tenerbaum, N., Burgess, A.R., Schneider, L.W. and Bents, F.D., (1999) "The interactive effects of age and sex on injury patterns and outcomes in elderly motor vehicle crash occupants", 3rd CIREN conference CA .

[4] Mertz, H., Dalmotas, D. (2007). Effects of shoulder belt limit forces on adult thoracic protections in frontal collisions. STAPP Car Crash Journal, Vol. 51, pp. 361-380

[5] Kent, R., Lee SH and Darvish, K., (2005) Structural and material changes in the aging thorax and their role in crash protection for older occupants', Stapp Car Crash Journal, Vol 49, 231-249

[6] E Haug, HY Choi, S Robin, M Beaugonin, (2004) Handbook of Numerical Analysis, Volume XII: Computational Models for the Human Body - Human Models for Crash and Impact Simulation, Elsevier, 297-361.

[7] Tamura, A., Watanabe. I., and Miki, K., (2005) Elderly human thoracic FE model development and validation, 19th Enhanced Safety of Vehicle, Washington DC, NHTSA.

[8] Choi, H.Y., Han, J.W., Lim, J.H., Yoon, K.H., and Park, Y.H. (2008) Elderly Human Body Modeling for Crash Safety Simulation, ICrash, Kyoto

[9] Kemper, A.R., McNally, C., Pullins, C.A., Freeman, L.J., and Duma, S.M., (2007) The Biomechanics of Human Ribs : Material and Structural Properties from Dynamic Tension and Bending Tests, Stapp Car Crash Journal, Vol 51, 235-237.

[10] VP Solutions: Explicit and implicit solver reference manual (2008), ESI Group

[11] Neathery, R. (1974). Analysis of Chest Impact Response Data and Scaled Performance Recommendations. Proceedings of the 18th Stapp Car Crash Conference.

[12] Shaw, G., Lessley, D., Crandall J., Kent, R., Kitis, L. (2005) Elimination of Thoracic Muscle Tensing Effects for Frontal Crash Dummies, SAE 2005-01-0307

[13] Kent, R, Lessley, D. and Sherwood, C. (2004), Thoracic Response to Dynamic, Non-Impact Loading from a Hub, Distributed Belt, Diagonal Belt, and Double Diagonal Belts, STAPP Car Crash Journal, Vol. 48, pp. 495-519 